\title{
Reviews
}

Clemente Marconi (ed.), The Oxford Handbook of Greek and

Roman Art and Architecture, Oxford University Press, New York 2015, pp. 710, ISBN 978-0-19-978330-4

$\mathbf{E}$ ven though the title gives a hint on the content, this book is more than a simple handbook. One of the most surprising facts is the diversity and the richness of the detailed information being brought together to present the newest references regarding the Greek and Roman art and architecture. This edition represents a collection of research ideas about the Greek and Roman cultural aspects. Furthermore, is dedicated to Salvatore Settis, a renowned archaeologist and historian of Italian art.

The book is structured in five parts, containing thirty articles, which marked the history of ancient art and architecture from theoretical and practical approaches to the interpretation of Greek and Roman times importance all the way to the current perception.

Part I, 'Pictures from the Inside` contains 4 articles presenting two sections, namely the ideas about Greek and Roman art and architecture and information about the written and artistic records.

Part II, 'Greek and Roman Art and Architecture in the Making' consists of 6 articles bringing up the difference between the eternal substance of an object and the external appearance, more exactly the difference between the production of images, buildings, the materials and the techniques used in their production.

Part III, 'Ancient Context' contains 7 articles. This part goes back to identifying the agents or forces behind the creation of art and architecture, the purpose of their creation and the way it was perceived.

Part IV, 'Post-Antique Contexts' is composed from 5 articles and discusses the issues of reception, as a historical phenomenon where different contributors, such as artists, architects and institutions, are the pawns in conveying, transforming and reinterpreting of the images and monuments of Greek and Roman heritage.

And the last but not the least, part V, `Approaches` with 8 articles presents vast theoretical implications, methodologies and directions of research in the field of study Greek and Roman art and architecture.

Right after the Contents, Acknowledgments, Abbreviations and Spelling, and Contributors, there is a complex Introduction - Advocating a Hermeneutic Approach signed by the editor of the book, Clemente Marconi. At the very end is placed the Index.

The editor affirms that the scope of this handbook is to explore key aspects of Greek and Roman art and architecture and review the larger theoretical frameworks, methodologies, and directions of research in this field. It also defines the audience, to which this book is dedicated, in the first place, graduate students with a particular interest in the study of Greek

\section{Xenia Păușan}

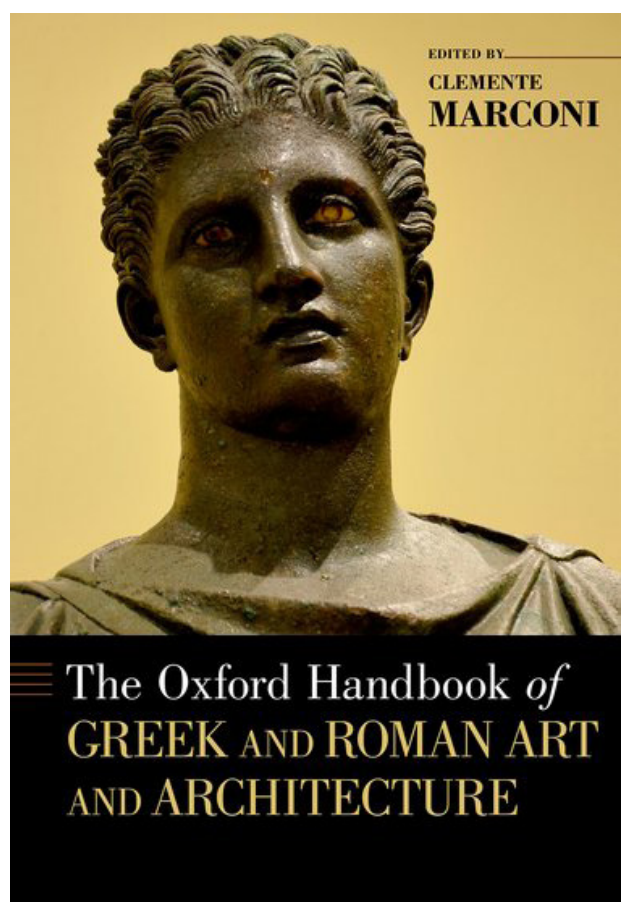


and Roman art and architecture. The main purpose of this handbook is to offer guidance by introducing students to the critical aspects of the theme and to the various modes of inquiry that have directed the discipline from its origins, as well as some future directions.

One important aspect of this book is its contributors, senior scholars, who have played a critical role in shaping the field, but also younger scholars having an equally important role in defining the discipline for future generations. Within this framework, the volume brings together scholars of various generations, nationalities, and backgrounds, to voice their opinion regarding art and architecture in Greek and Roman times. This book contains over 150 line drawings and images used to underline the important aspects of this subject.

The art and architecture of Greek and Romans are bought in a common discussion for two reasons: first the information we hold today about the Greek culture is a result of perception and its transmission through Roman eyes, and secondly, the Greek culture is an essential component of the Roman culture. The references are marked in the text, making the reading a bit difficult to follow. Despite that, it is easy to observe that most of the references are recent papers, underlining the well researched and documented procedures. Each article has more than one heading and at the end of it the bibliography is presented.

As we underlined before, the book represents more than a handbook, being a collection of thirty articles structured in five parts. Therefore, we decided to review each article individually.

The first chapter, 'Greek and Roman Theories of Art' by Deborah Steiner, illustrates how art was perceived in that period and explores the art theory not only through the ideas of different philosophers but through a wider view over the Greek and Roman literature and epigraphy. Each artwork it is analyzed not only by its message, but also by its material and function.

Homer, Pindar and many other sources imagine craftsmanship as a gift of the Gods. Still, Callimachus in Iamb 6 indicates that techne is a skill that stands independent of and opposed to the innate genius or divine inspiration. In Dio's Stoic, the artist's innate conception of the divine allows him to fashion the God, while Maximus of Tyre uses phantasia as a secondary manifestation, a mimēsis to describe the 'mental presentation' that Phidias's piece transmits. In this chapter by focusing on images, the very notion of `ancient art history` is questioned.

Chapter 2, 'Greek and Roman Architectural Theory' by Mark Wilson Jones, focuses on practice and anticipates theory in the development of human endeavors, because thinking is creating. By contrast, ancient Greek and Roman architectural theory was one and the same: a similar appreciation for materials, scale, and precision unites. Vitruvius's treatise will always remain the starting point for investigating both Greek and Roman architectural theorys. Vitruvius indicates three fundamental prerequisites for a successful piece of architecture (De arch. 1.3.): firmitas, utilitas, venustas, not just for building (aedificatio), but also for chronometry (gnomonice) and engineering (machination). Each construction plan must respect the three principles formulated by him, namely symmetria, eurythmia and decor. In the second part of the chapter, the design of ancient buildings is being discussed, supported by many examples, starting from the idea that stands at the base of their construction.

In chapter 3, 'Greek and Roman Specialized Writing on Art and Architecture' by Francesco de Angelis, the different forms of writing about the art and architecture of that time are discussed, with a special emphasis on the writings of the artists themselves. In this chapter it is revealed that many of the antique sources are pure theoretical and do not combine what it was known with what it was created. Furthermore, the chapter explores the use of writing to control and standardize procedures, to reinforce memory, to shape thinking and to extend communication.

Chapter 4, 'Greek and Roman Images of Art and Architecture by Maryl B. Gensheimer, follows the representation of images andbuildings. These representations are a very important part in understanding the creators and the reception of their work. The reception of images depends, to a certain extent, on the preconceptions of the viewer. Vase production played a role in the interpretation of the meaning of divinity representation. By document sources, the frieze from the Praedia of Julia Felix presents details of the ancient cityscape that have been lost. This frieze and metapictures of statues and columns provide a vivid scene of the ancient city. The images of architecture within the various marble plans of Rome are intended to encapsulate a sense of authority and order. The vase painting, the friezes and marble plans illustrate aspects of how the images were seen in ancient times, created for both public and private contexts.

A detailed chronological historiography about Greek and Roman artists is presented at the beginning of chapter 5, 'Greek and Roman Artists` written by Rainer Vollkommer. In the period of Greeks and Romans there was no boundary between 'artist' and 'craftsman'. The word 'technē', in Greece, describes all kind of manual activities, meaning craft, skill and knowledge. In Latin, 'ars' describes the activities such as hard work and labor performed by people who could not afford to have leisure and time for politics. From a diachronic point of view, the first example of Greek signature of an artist is found on vases. Most of the signatures identified belonged to sculptors and half of them are from the Roman to Byzantine period. It is known that artists from the IV century BCE had a strong personality and were often depicted as wearing glamorous clothes or by giving away their artwork, which was considered to be too valuable to be sold. As for the payment, sculptors were remunerated depending on the size of the relief. Most of the sculptors and painters were paid like other laborers, just a few of them were lucky to be highly paid thanks to their fame. The most expensive works of art from that period that are known today are paintings. The possibility that artists were women 
was very rare. The evidence relies entirely on literary sources which point two domains in two time periods: painters in Hellenistic period and goldsmiths in Roman Imperial period.

The knowledge about Greek and Roman artists is generally limited by the remaining evidences. New findings might change the aspects and interpretation about artists' lives and works.

Chapter 6 'Greek and Roman Architects' by Henner von Hesberg, depicts the persons that were behind each great monument built, the architects. 'What kind of people were these architects? How were they seen in ancient times?' are just a few of the questions answered in this chapter. Being an architect, in the perception of ancient contemporary society, meant that the person was an intellectual, raised above the level of simple craftsmen, but without having an income higher than the craftsmen.

It is not defined clearly what was exactly the basis for an outstanding reputation for classical period architects, but it is concluded that other qualities, and not the design skills as in the contemporary society, had an important role, as the ability to coordinate the construction process, as well as to solve specific technical problems. What is known about Greek and Roman architects comes from diffuse references, from ancient sources and from inscriptions. Most of those inscriptions belong to the Greek world, because in Roman times they were stored in archives, rarely written on stones.

How detailed was the architect's work? How precise was it? It is known that the architect had to approve the models or samples, but there was no guarantee for the execution of the original design.

According to the Homeric poems, there were no experts in planning mention in the early Greek period. Still, it can be deduced that planning and execution seemed closely connected, where the patron gave the important instructions. The information preserved from the inscriptions shows that an architect had to take part in the selection of the location, to verify that all the measurements were correct, manage the payments, approve the work and oversee each detail. In this chapter, we learn about some Greek architects, about their work and projects from other writers, from inscriptions or from their own stories. The concept of architecture in Italy developed at first under similar condition to those from Greece, by implying the presence of an executing planner and a supervisor who was responsible for the construction. From the Vitruvius's writings, today are known the names of some architects. In addition, in his writings, it is specified the significant changes in the training and profession of architects in the Roman period, where a number of them were trained in the context of the army. The main purpose of Roman architects was to create the greatest possible effect with minimal costs. That was also interpreted in Roman architecture, precision of execution was less important than the logistical management of the enormous projects.

The next two articles discuss about patronage, financing and sponsorship of the art and architecture. Chapter 7, 'The Patronage of Greek and Roman Art' written by Eric R. Varner, deals with art's patronage. Art historical interpretation is focused on the patrons, because most of the
Greek and Roman artworks are anonymous and unsigned. The identities and social classes of patrons came through inscriptions and ancient textual sources. For the writer, patrons are both agents and authors of the works they commission.

As for chapter 8, 'The Patronage of Greek and Roman Architecture' by Bonna D. Wescoat, it continues the previous chapter with the story of two rulers, Alexander the Great and Octavian Augustus. Both were patrons from three major senses: they offered support to individual architects; they have funded public architectural projects that repaid in personal, political and social benefits and at the same time they were manipulators of the art in order to make demonstrative statements.

For art, the personal patronage is an unequal relationship where the patron sponsors or fosters the dependent artist, offering financial support, providing opportunities which benefit both the artist and the art. A special powerful medium for the patrons to express, in the civic code, is architecture because it was the most expensive long-lasting expression. During that period, people with power, financial resources and the desire for lasting recognition invested in architecture. There were different purposes why a patron financed a construction, two of them which were often mentioned are opportunity and obligation. Architecture had the capacity to shape and change people's life. Regarding these reasons, Greek and Roman patrons took advantage of it, which allowed them to influence the population.

Having a very deep connection with archaeology, in the following two articles the essential role of the technical and scientific analysis used in the study of Greek and Roman art and architecture is discussed.

In chapter 9, 'The Materials and Techniques of Greek and Roman Art' by Kenneth Lapatin, is mentioned that the Natural History of Pliny the Elder is the most important ancient text which survived for the study of materials and techniques of many kinds, especially the last five books (33-37). The fourth-century CE Greek papyri from Egypt are focused on the work of Pliny by presenting hundreds of recipes for a number of crafts. Many types of materials and techniques were used by the craftsmen in ancient time, being selected based on its natural proprieties and visual characteristics. The most commonly used material was clay because it was cheap, malleable, ubiquitous, being considerate the plastic of antiquity. Different stones were used for a variety of purposes, some types of stone had political and economic implication. Gold, silver, copper, iron, lead, bronze were the most important alloys used by ancient craftsmen. On panel and fresco, painting was widely practiced in Greek and Roman world, particularly in the second period. How and why Greek and Roman craftsmen choose some materials can be deducted by understanding the sources and proprieties of specific materials and the symbolic, cultural and political values attributed to them.

Chapter 10, 'The Materials and Techniques of 
Greek and Roman Architecture` written by Pier Luigi Tucci, focuses on detailed descriptions of several architectural monuments. An important matter of today's research is to investigate the historical context of ancient buildings and to place antique architectural practices into a larger social and cultural-historical view. In this chapter the common materials used in construction (mainly wood, stone, metal and clay) are also described. Wood was the earliest material used for building because it was easily shaped and widely found. Due to its low resistance, people began a search for new type of materials which could be used in major building projects. Soon after, stone became the most used material in construction during the first half of the sixth century BCE. There are no construction entirely sustain on metal, this material being mainly used to maintain the pieces together. As the ancient society started to develop, the new materials based on clay (e.g. burned bricks) lead to a new era in the development of constructions. One surprising aspect of this article is the use of geological information regarding the materials used in construction, like lithic material, as well as the main sources from where it was brought. Inspired by the Etruscans and the Greeks, the Romans builders had their own development. From the sixth century BCE onward, most of the buildings in Rome and central Italy were consolidated in stone. The most common stones used were the local volcanic conglomerate, tuffs. As the Roman Empire expanded, new tuff quarries were used, having a stronger tuff and new types of rock were discovered like travertine and basalts. Even though, one of the differences between Greek and Roman architecture refers to the design of the stone columns, the most important Roman contribution to building technology is the systematic use of concrete. The brick production had a major impact on Roman building development, from bricks for masonry, to tiles, and many other clay products. The use of arch was brought to a whole new level once transformed into concrete constructions, which lead to the large-scale vaulted structures, that is considered by the author one of the most significant Roman contributions to the history of building technology.

All the studies regarding the design, materials and techniques of Greek and Roman architecture should also be analyzed in comparison to the architecture in ancient societies, in order to establish a connection between the construction space and their inhabitants. These analyses should involve an interdisciplinary work for a better understanding.

The author of chapter 11, 'The City in the Greek and Roman World', Jamieson C. Donati, introduces the concept of urban environment. Centuries before the Greek and Romans, in Mesopotamia and Egypt, cities existed as a conglomeration of people coexisting within durable structural forms and sharing a system of cultural norms. Still, the most innovative part of the Greek and Roman urbanism consists in their ability, to transform their environment in order to match the needs of a changing population. This chapter also contains a short yet very compact historiography of the evolution of Greek and Roman cities. The most important turning points of the city's evolution are marked. A chronological evolution of the Greek city is presented, starting from the Early Iron
Age through Classical and Hellenistic period. At the end of the Classical period, dynasts were those who had an impact regarding the changes in the construction preferences, selecting big grandiose houses and then transforming some of the parts into semi-public places.

During the Middle Roman Republic, most of the colonies were organized within an orthogonal plan dividing the city into public, religious and residential areas. In Late Roman Republic, the basilica becomes a quintessential architectural element of the Roman forum. The use of concrete and stone allowed the Romans to build enormous porticoes. As the construction techniques evolved, buildings and venues for public spectacles and games were built: theatres, circuses, amphitheatres and odeia. During the Principat, these major changes were inaugurated. Rome and the other cities became instruments to consolidate the power of the emperor. At the end of the chapter, a conclusion is drawn: the city is a flexible, man-made instrument that takes shape and is continuously modified at any time to serve its inhabitants.

The next two papers analyze the wide variety of functions of images in Greek and Roman times. Chapter 12. 'The Functions of Greek Art' of Olga Palagia, explores the use of art in the Greek society. From the mid-seventh century BCE, Greeks began to create images on monumental scale for the divine, commemorating and in honour of men and women. All the artwork was being revolved around the human body. The article follows two main directions, the sculptures and paintings of the Greek art. What was the role of a statue? Why it was placed in a sacred context? And why most of the statues are female representations? Are just a few questions answered in this article. Moreover, sculptures were also integrated into the decoration of the temples and stoa: Ionic temples were decorated with sculptural friezes, Doric temples with sculptural metopes, and for the Hellenistic stoas was used relief friezes. At first, painting was entirely reserved for sacred places, but after the Peloponnesian War this rule was bypassed as the surviving paintings of Macedonia present the world of the royal court and not the democratic societies.

Chapter 13, 'The Functions of Roman Art' written by Paul Zanker, explains the Roman art implications. One interesting aspect of this chapter is the beginning of it with the following questions: what purpose did art have for the Romans? why some arts were placed in a specific space? And what function did this art have there? In this chapter the function of art in two places is discussed, in public spaces as squares, streets, sanctuaries and private spaces, as houses and villas. Sculptures and paintings in private space had the purpose to distract the owners from their everyday life problems and were meant to seduce the viewer to dream, to feel and to ponder. The forum became the main place to locate honorary statues of politicians and generals, although those statues remain a particularly effective tool for political advertisement.

The next two articles follow the use of images even further by exploring the relationships between built 
environments, images and rituals.

Can a specific activity be understood as ritual? This question stands at the base of the $\mathbf{1 4}^{\text {th }}$ chapter, 'Buildings, Images, and Rituals in the Greek World' by Joannis Mylonopoulos. Rituals and rites are taken as parameters which influence sacred architecture and religious imaginary. This article presents in details the elements of a temple and a stoa, and their connection to the sacred. Another aspect presented here is the importance of paintings on the pottery vases from the Archaic and Classical periods. Most of the themes decorating temples, treasuries and other structures of religious character are mythological rather than cultic. We learn that architecture was the decisive parameter in the spatial and visual definition and organization of any sacred space, being eventually defined by the ritual activity.

As for the Roman world, in chapter 15, 'Buildings, Images, and Rituals in the Roman World' by Richard Neudecker, are presented the materials used for the construction of the sacred buildings from the Republican to the Late Imperial period. Some of the scholars consider that architecture is a cultural indicator and buildings are social objects. It is necessary to understand the relationship between buildings, images, and rituals in order to establish their correct function. The buildings associated with the hierarchies of Roman social life are the ones with a great impact on cultural spheres of action. The religious buildings were the most elaborate in terms of design, the richest in decoration and the highly enduring in their conception.

The next two articles are connected, both presenting the analyses of the ancient reception for Greek and Roman art and architecture. In chapter 16, 'The Roman Reception of Greek Art and Architecture` by Rachel Kousser, the interaction of Roman with Greek art is shown as being varied, pragmatic and widespread. Most of the Greek art was copied into the Roman time in such a way that the Greek works were adapted to satisfy the need of the Romans.

In chapter 17, 'Roman Art and Architecture in the Provinces and beyond the Roman World by Natalie Kampen, the discussion follows the principle central-provinceperiphery, a model created by Michelle Marcus (1990) for Near East. This model can be used, to a certain point, to describe all the territorial and social relationships. Still, this delimitation does not take into consideration the constant fluidity of historical development. Different scholars had tried to present some aspects of cultural visions of the Roman world, most of them reduced their interest to local and regional aspects.

Chapter 18, 'The Post-Antique Reception of Greek and Roman Art' by Lucia Faedo, presents a large introduction about the reception of Greek and Roman art and architecture, by starting with the Middle Ages to the twentieth century. The main focus is on Italy, because this country played an important role in the Early Modern era, an era where the major emphasis falls on the artists and architects engaged into this process.
An interesting aspect of this article, chapter 19, 'The Historiography of Greek and Roman Art and Architecture' by A.A. Donohue, resides in the fact that right from the beginning the contour of the main theme is marked, the focus on the historiography, a process in which the history of art and architecture of Greek and Roman period is written and the specific studies connected with it are conceived.

Chapter 20, 'Conserving of Greek and Roman Architecture from John H. Stubbs is the only article which offers information about how the heritage can be protected and who can contribute to this process. Right after their creation, ancient buildings need to be restored, rehabilitated, reconstructed and preserved. At the beginning of the nineteenth century, legislation measurements were adopted in Rome regarding the historic monument protection. This was just the beginning, soon after, other European countries also took caution measurements for protecting theirt historical monuments. A few important charts were created and adopted, as the Athens Charter (1931) and the Venice Charter (1964). These charts established an international guidelines for practice in architectural conservation. Whichever line of intervention is chosen, long-term conservation should respect its historic physical and aesthetic integrity. In this chapter, different terms are defined, as it follows: preservation or conservation, preventive conservation, maintenance, consolidation or stabilization, restoration, rehabilitation or renovation, reconstruction, relocation, replication, re-restoration. Specialists who take on the task of architectural conservation should follow four main phases: project identification, research and planning, implementation and maintenanceprotection-sustainability.

In chapter 21, 'Displaying Greek and Roman Art in Modern Museums' by Beth Cohen, the idea of permanent museums is discussed, following the ones devoted to ancient art, to archaeological-site museums and the university museums. One important aspect presented in this chapter is the museum display environments for Greek and Roman art, from the Early Modern period to the present, and its importance of how a viewer precepts the ancient art.

Chapter 22, 'Greek and Roman Art and the Debate about Cultural Propriety' by Margaret M. Miles argues about the proper ownership of Greek and Roman art. Because, art is considered the identity of one country. This chapter follows two ideas, first is about looting and the effort to reduce this action and the effect it can have on the reception of Greek and Roman art, and the secondly the importance of protecting artworks both in museums and on the archaeological sites.

The chapter 23, 'Connoisseurship' by Adolf $\mathrm{H}$. Borbein, follows an interesting approach. Since the antiquity, the way of identifying the authors has been based only on assumptions as most of the works of art have not been signed and the ones with signature of the creator are just a few. Statius considered that a connoisseur recognizes the style/ductus of ancient/veteres artists and can also attribute unsigned pieces to them. In January 1506, Giuliano da 
Sangallo and Michelangelo were the first ones to discover that the Laocoon group was the work of Rhodian sculptors Hagesander, Polydorus and Athanodorus mentioned by Pliny. Another marking point was the work of J.J. Winckelmann, who was the first one who attempted to write art history as a history of the development of artistic forms and not as a history of artists, in his Geschichte der Kunst des Alterthums (1764). It is impossible to associate the copies of ancient Greek paintings with the Greek artists, because the lack of any historical evidence. On the other hand, it is not possible to make any connections between the Greek copies from the Roman period with the original ones from the Greek time, because the first ones were adjusted in order to confirm the Roman principles of composition. In antic and epigraphical sources only a few Roman painters are mentioned. A good solution in search for the masters of the artworks is the use of both written and archaeological sources.

Chapter 24, 'Formal approaches` by Christian Kunze, the notion 'style' is at the base of a concept regarding exposition and interpretation of images from antiquity. This term comes from the Latin word stilus, which is a written instrument. From the fifteenth century, the term was used to describe a characteristic manner of literary and rhetorical expression. Also, this term implies that individual formal attributes of an image are connected with one another. The term can be applied not only to individual objects, but also to attributes of an artist's oeuvre, as personal style, to a large group of works or an artistic genre, as genre style, or to a specific period of time, as epoch style. The meaning of 'style', in terms of its 'use', is a sum of all the observable relationships and consequences with which style is connected. Greek and Roman archaeology, as well as art history, are the ones to answer further problems regarding how antic images are see and presented to the viewer.

Chapter 25, Iconographical and Iconological Approaches' by Cornelia Isler-Kerényi, focuses on the current study of the Greek and Roman art, in particular ancient iconography, by taking into consideration the documentation and classification of images, in order to gain a deeper understanding of the ancient Greek and Roman culture. Moreover, this chapter aims to obtain a comparison between the ancient culture and the contemporary world. The main study focuses on Greek vases and Roman sarcophagi, which are placed into the cultural and historical context to which they belong. We need to question the very roots of how we see and interpret the ancient images of Greek and Roman culture by taking into consideration the gap between the ancient pagan and the polytheistic world, as well as the Christian and Modern Europe. The author points out that using the methodology of Panofsky in the study of Greek and Roman art is in vain, because of the many differences between Renaissance paintings and ancient images, where the images on the Greek vases and Roman sarcophagi do not reflect the reality as it is Renaissance paintings. Therefore, a new approach is needed in order to understand and interpret ancient images.

The chapter 26, 'Sociohistorical approaches' written by Burkhard Fehr, presents a way of associating images with different approaches in order to obtain a bigger picture of the art, where the main actor is not the artist himself but a part of a larger group. On the other hand, it is well founded the concept stating that art is a world of its own (l'art pour l'art), where its core is not even touched by external social factors. Still, the sociological approach of the Greek and Roman art is focused neither on personalities, nor the artist, but it starts from the characteristics and interests of smaller or larger group of individuals and follows their interest in the rules that connect the group to its art. The relationship between different categories of social hierarchies and how these images were seen by the intellectual viewer depends on the maker of the paintings or on the constructor of architectural monuments, because we have to keep in mind that each artist was part of a social context.

Chapter 27, 'Gender studies` by Caroline Vout, starts with the question 'How confident are we that we know what we are looking at, that it looks as it did in antiquity, that we see in the same way as the ancients? and follows the impact on how scholars interpret the Greek and Roman art and architecture by trying to explain certain aspects. One of these aspects is the concept of 'gender', which was analyzed based on the body descriptions, interactions and gestures by the ancient authors and artists and placed it into a larger grid with social characteristics.

It is known that anthropology plays an important role in the studies of Greek and Roman art, but it can not be described by a set of principles because of the discontinuity and eclecticism of the subject. Therefore, chapter 28, 'Anthropological Approaches' by Gloria Ferrari, follows a historiographic overview with some general considerations. Carl Robert, in the nineteenth century, concluded that the relationship between the visual and the verbal was formulated in terms of a structural analogy. Based on his theory, Mortiz Lazaurs and Heymann Steinthal concluded that the rules that govern the human societies are dependent on historical and social factors. All the issues around 'art' as a privileged category of cultural production cannot be submitted under false categories such as 'material culture` or 'visual culture`. What is art and how art operates in society, these concepts have been recently introduced in the field of anthropology. The Greek and Roman art should be seen as a product of cultural expression and social practice.

In chapter 29, 'Theories of Reception' by Michael Squire, is discussed the difference between past and present regarding art and how it is received. The way we see Greek and Roman antiquity goes through the lens of the modern world. Reception is a way of rebuilding intellectual bridges between the disciplines of classics and art history.

The scientific exploration of the artworks is based on three principal questions of meaning, function, and agency: what images represent, how they were used, and what they bring about. Meaning, the most important one in the art of visual can be expressed on five different levels: factual meaning or subject matter, conceptual meaning 
or significance of images, explicit historical messages of images, implicit historical meanings of images - valued in their significance from the perspective of modern historians, actualized meaning if images - presented according to the experiences and concepts of modern observers. In the last chapter of this book, chapter 30, 'Semiotics to Agency' by Tonio Hölscher, it is explained the understanding of the historical art as visual form by referring to bodies and object, attitudes and actions, compositions and style. The image of the human body, with its qualities and capacities, is the main piece in the understanding of the Greek and Roman art. A bridge can be built between cultural theory and art based on the body's postures.

This assemblage of articles offers the possibility to go beyond of what a handbook can offer, by collecting different theories and ideas, but maintaining the purpose of the book to bring light in the studies of Greek and Roman art and architecture. Even though, this book was conceived for scholars and students with an interest in the field, the book is well structured so that anyone can gain an overview idea of the reception of the subject. The book starts with different theories leading the reader through exploring the Greek and Roman art and architecture and by placing it in both ancient and post ancient context, as well as approaching this subject from different angles.

It is an innovative book by bringing together specialists and their ideas into the context of Greek and Roman art and architecture research. Each contribution gives new perspectives upon a wide range of subjects.

By using recent references and a new approach, this book should be a starting point for anyone interested to explore the subject presented. 